\title{
Effect of high light intensity on the photosynthetic apparatus of two hybrid lines of Paulownia grown on soils with different salinity
}

\author{
M. STEFANOV*, E. YOTSOVA*, Y. MARKOVSKA ${ }^{* *}$, and E.L. APOSTOLOVA* ${ }^{*+}$ \\ Institute of Biophysics and Biomedical Engineering, Bulgarian Academy of Sciences, \\ Acad. G. Bonchev Str. 21, Sofia 1113, Bulgaria* \\ Faculty of Biology, University of Sofia, 8 Dragan Tsankov Blvd., 1164 Sofia, Bulgaria**
}

\begin{abstract}
The objective of this investigation was to evaluate the simultaneous action of light stress and salinity. Pulse amplitude modulated chlorophyll fluorescence, $\mathrm{P}_{700}$ redox state, and pigment analysis were used to assess the impact of high light intensity on Paulownia tomentosa $\times$ fortunei and Paulownia elongata $\times$ elongata grown on soils with different salinity. It was found that light stress reduced the amount of pigments and the efficiency of photochemical energy conversion, inhibited the maximum and the effective quantum yields of PSII photochemistry, decreased photochemical quenching and photosynthetic rate. Data also showed influence on the primary quinone acceptor $\left(\mathrm{Q}_{\mathrm{A}}\right)$ reoxidation, which led to the restriction of the electron flow from $\mathrm{Q}_{\mathrm{A}}$ to plastoquinone and stimulation of the cyclic electron flow. The possible reasons for the increased effects of the light stress under conditions of high salt concentration in soil for Paulownia tomentosa $\times$ fortunei are discussed.
\end{abstract}

Additional key words: leaf, light sensitivity, photoinhibition, rate constant, salt tolerance.

\section{Introduction}

Stressful environments cause alterations in a wide range of physiological, biochemical, and molecular processes in plants, which influence their growth and development (Ashraf and Harris 2013). In nature, plants are subjected often to the simultaneous action of several abiotic stress factors. The salt stress and high light intensity (light stress) are major environmental stressors that have a strong influence on the photosynthetic efficiency (Allakhverdiev et al. 2002). The exposure of plants to excess excitation light, which they cannot use or that it cannot be successfully dissipated, leads to decreased efficiency of the photosynthesis (Goh et al. 2012, Vass 2012). Light- induced decrease of the photosynthetic efficiency, when the plants are illuminated with excess light, is called photoinhibition, which is the subject of intense research over the last decade. Photoinhibition affects all the components of the photosynthetic apparatus and their interactions, as a primary site of action is the PSII complex (Aro et al. 1993b, Takahashi and Badger 2011, Vass 2012). In the literature, two schemes for the mechanisms of photoinhibition have been discussed. According to the first one, strong light induces production of reactive oxygen species (ROS), which directly inactivate the reaction center of PSII, while according to the second one,

Received 10 February 2017, accepted 11 April 2017, published as online-first 18 May 2017.

${ }^{+}$Corresponding author; phone: +359-2 97926 21, fax: +359-2 97124 93, e-mail: emya@bio21.bas.bg

Abbreviations: $\mathrm{A}_{1}$ - amplitude of the fast exponent of dark reduction kinetics of reaction center of PSI; $\mathrm{A}_{2}$ - amplitude of the slow exponent of dark reduction kinetics of reaction center of PSI; Car(s) - carotenoid(s); Chl - chlorophyll; DAS - dark-adapted state; $\mathrm{EE}_{0}-$ Paulownia elongata $\times$ elongata grown in nonsaline soil; $\mathrm{EE}_{1}-$ Paulownia elongata $\times$ elongata grown in soil type $1 ; \mathrm{EE}_{2}-$ Paulownia elongata $\times$ elongata grown in soil type 2; ETR - linear electron transport rate; $\mathrm{F}_{0}$ - minimal fluorescence level; $\mathrm{F}_{\mathrm{m}}-$ maximal fluorescence level; $F_{v} / F_{m}$ - maximum quantum yield of PSII photochemistry; $F_{v} / F_{0}$ - ratio of photochemical to nonphotochemical processes; $\mathrm{F}_{\mathrm{v}}{ }^{\prime} / \mathrm{F}_{\mathrm{m}}{ }^{\prime}$ - effective quantum yield of PSII photochemistry; ФPSII - the effective quantum yield of photochemical energy conversion of PSII; $\mathrm{k}_{1}$ - fast rate constant of maximal chlorophyll fluorescence relaxation; $\mathrm{k}_{2}$ - slow rate constant of maximal chlorophyll fluorescence relaxation; $\mathrm{k}_{1}{ }^{\mathrm{P} 700}$ - fast rate constant of dark reduction kinetics of reaction center of PSI; $\mathrm{k}_{2}{ }^{\mathrm{P} 700}-$ slow rate constant of dark reduction kinetics of reaction center of PSI; LAS - light-adapted state; LIC - light-induced change; $\mathrm{P}_{700}$ - reaction center of PSI; qP - photochemical quenching coefficient; $\mathrm{R}_{\mathrm{Fd}}-$ chlorophyll fluorescence decrease ratio; $\mathrm{TF}_{0}-$ Paulownia tomentosa $\times$ fortunei grown in nonsaline soil; $\mathrm{TF}_{1}-$ Paulownia tomentosa $\times$ fortunei grown in soil type $1 ; \mathrm{TF}_{2}-$ Paulownia tomentosa $\times$ fortunei grown in soil type 2 .

Acknowledgements: This work was supported by the Bulgarian Academy of Sciences and the Program for career development of young scientists, BAS (Contract ДФНП-138/12.05.2016). The authors are grateful to Bio Tree for providing the plants. 
the photodamage is initiated by a direct effect of the light on the oxygen-evolving complex and that ROS inhibit the repair of PSII by suppressing the protein synthesis (Murata et al. 2007). Previous studies have shown that high light intensity causes structural changes at the acceptor side of PSII, delay of the electron transport from $\mathrm{Q}_{\mathrm{A}}$ to $\mathrm{Q}_{\mathrm{B}}$ (secondary quinone acceptor), and damage of the $\mathrm{D}_{1}$ protein in PSII (Vass 2012). Hakala et al. (2005) assumed that the change at the donor side of the PSII is a result of the release of $\mathrm{Mn}$ atoms from the oxygen-evolving complex, which occurs after damage of the PSII reaction center. The extent of PSII damage by excess light depends on the balance between the rate of photodamage and the rate of its repair (Murata et al. 2007, Takahashi and Murata 2008, Kirchhoff 2014). It has also been found that at light stress, changes occur in the complex of PSI too, which leads to degradation of the proteins of the reaction center and an inhibition of the iron-sulfur centers (Sonoike 1996, Barth et al. 2001).

Soil salinity is one of the most serious environmental factors limiting the crop productivity in all over the world (Misra et al. 1997, Parida and Das 2005, Jiang et al. 2017). The effects of salt stress on the plants are attributed to osmotic stress due to lowering of the external water potential, the toxic effects of the ions or a combination of the two (Kingsbury et al. 1984, Grieve and Suarez 1997, Hasanuzzaman et al. 2009, 2013). Salinity has an impact on the growth, metabolism, and the photosynthetic efficiency of plants (Ioannidis et al. 2009, Ashraf and Harris 2013). The decrease of the efficiency of the photosynthesis is a result of structural changes in the thylakoid membranes, which are related to the disintegration of the granna and damage of the stromal thylakoids (Shu et al. 2012). It has been found that salinity decreases the amount of the pigments (chlorophylls and carotenoids) as these changes depend on the salinization and its duration (Misra et al. 1997, Ashraf and Harris 2013). Previous investigation revealed variation of the impact of salt stress on PSII depending on the plant species. Some investigations have

\section{Materials and methods}

Plant material: Two hybrid lines of Paulownia, Paulownia tomentosa $\times$ fortunei $\left(\mathrm{TF}_{0}, \mathrm{TF}_{1}, \mathrm{TF}_{2}\right)$ and Paulownia elongata $\times$ elongata $\left(\mathrm{EE}_{0}, \mathrm{EE}_{1}, \mathrm{EE}_{2}\right)$, were used in this study. The conditions for plant cultivation were as in Stefanov et al. (2016). The plants were grown in three types of soils with different salinity: nonsaline (type 0) and two saline soils (type 1 and 2) with electrical conductivity of $1.6 \mathrm{mS} \mathrm{m}^{-1}, 6.3 \mathrm{mS} \mathrm{m}^{-1}$, and $14.0 \mathrm{mS} \mathrm{m}^{-1}$, respectively. A more complete description of the composition of the soil is given in Stefanov et al. (2016). The soil types, on which plants were grown, are given in the index. The plants were grown under controlled conditions (temperature: $30^{\circ} \mathrm{C}$ day $/ 15^{\circ} \mathrm{C}$ night, relative humidity: $40-65 \%$ ) in a greenhouse. Details for the cultivation of the plants are given in shown that the high salt concentration inhibits activity of PSII (Loreto et al. 2003, Akram and Ashraf 2011), while others demonstrated that PSII activity remains unchanged (Lu et al. 2002, 2003). Differences have been also shown in polypeptide composition of PSII in salt-tolerant and salt-sensitive plant species (Wang et al. 2009).

In nature, the plants grown in saline soils often absorb light in excess for a few hours during midday, but the investigations for the simultaneous influence of salinity and high light intensity are limited. Studies with sorghum, wheat, and barley have revealed an increase of the PSII inhibition under high light, when the plants are grown under conditions of salt stress, and the effect is enhanced by increasing the degree of salinization (Misra et al. 1991, Masojídek and Hall 1992, Sharma and Hall 1991, Nishiyama et al. 2006). On the other hand, the investigations of halophyte Suaeda salsa have shown that this plant is resistant not only to salinity stress but also to the light stress (Lu et al. 2002).

Chlorophyll (Chl) a fluorescence is often used in biological and agricultural research as an indicator for changes in plants under different abiotic and biotic stresses (Dąbrowski et al. 2015, 2016, Kalaji et al. 2017). The measured parameters are in a close correlation with the function of PSII. Stress applied to plants affects the photosynthetic mechanisms and changes the Chl fluorescence yield (Dąbrowski et al. 2017). In our previous studies, using Chl fluorescence, we found that two new hybrid lines of Paulownia (Paulownia tomentosa $\times$ fortunei and Paulownia elongata $\times$ elongata) are resistant to soil salinity and therefore are suitable for phytoremediation of saline soils (Stefanov et al. 2016). The study also revealed a small variation in the impact of soil salinity on the photosynthetic apparatus of these lines. The aim of the present study was to evaluate the influence of high light intensity on the pigment composition and on the functions of photosynthetic apparatus in Paulownia tomentosa $\times$ fortunei and Paulownia elongata $\times$ elongata grown on soils with different salinity.

Ivanova et al. (2014). For the experiments, mature leaves from two-year-old plants were used. Paulownia seedlings were obtained from Bio Tree (Bulgaria).

High-light treatment: The detached leaves from two hybrid lines of Paulownia plants were illuminated at room temperature for $4 \mathrm{~h}$ with light intensity of 1,500 $\mu$ mol(photon) $\mathrm{m}^{-2} \mathrm{~s}^{-1}$. The control leaves were kept in dim light at room temperature. For characterization of the effect of the light stress on the studied parameters, we introduced the parameter LIC (light-induced changes), which is the ratio of the value of the studied parameter after light treatment to the value of the control (before the light treatment). 
Pigment analysis: The pigments were determined after extraction from leaves with $80 \%$ acetone. After centrifugation at $4^{\circ} \mathrm{C}, \mathrm{Chl} a, \mathrm{Chl} b$, and Car were determined spectrophotometrically in the solution at 663.2, 646.8, and $470 \mathrm{~nm}$. The measurements were made on Specord 210 Plus, Edition 2010 (Analytik Jena AG, Germany). The equations of Lichtenthaler (1987) were used for determination of the amount of Chl $a, \mathrm{Chl} b$, and carotenoids (Car):

$$
\begin{aligned}
& \text { Chl } a\left[\mu \mathrm{g} \mathrm{m}^{-1}\right]=12.25 \times \mathrm{A}_{663.2}-2.79 \times \mathrm{A}_{646.8}, \\
& \text { Chl } b\left[\mu \mathrm{g} \mathrm{m}^{-1}\right]=21.50 \times \mathrm{A}_{646.8}-5.10 \times \mathrm{A}_{663.2}, \\
& \text { Car }\left[\mu \mathrm{g} \mathrm{m}^{-1}\right]= \\
& =\left[1,000 \times \mathrm{A}_{470}-1.63 \times \mathrm{Chl} a-104.96 \mathrm{Chl} b\right] \times 198
\end{aligned}
$$

Chl fluorescence: Pulse amplitude modulated (PAM) Chl fluorescence was measured on leaf discs using a fluorimeter (PAM 101-103, H. Walz, Effeltrich, Germany). The measurements were made as in Stefanov et al. (2016). The leaves were dark-adapted for $30 \mathrm{~min}$. The intensity for measurements of the minimal fluorescence level $\left(\mathrm{F}_{0}\right)$ in dark-adapted state (DAS) was $0.02 \mu \mathrm{mol}$ (photon) $\mathrm{m}^{-2} \mathrm{~s}^{-1}$. The maximal fluorescence levels, $F_{m}$ (in DAS) and $F_{m}{ }^{\prime}$ in light-adapted state (LAS), were determined by saturating flashes $\left[2,500 \mu \mathrm{mol}\right.$ (photon) $\left.\mathrm{m}^{-2} \mathrm{~s}^{-1}\right]$ which were provided by Schott lamp KL 1500 (Schott Glaswerke, Mainz, Germany). The actinic light intensity was $250 \mu \mathrm{mol}$ (photon) $\mathrm{m}^{-2} \mathrm{~s}^{-1}$. The following parameters were used for characterization of the impact of the stress factors on the studied Paulownia lines: the maximum quantum yield of PSII photochemistry, $\mathrm{F}_{\mathrm{v}} / \mathrm{F}_{\mathrm{m}}=\left(\mathrm{F}_{\mathrm{m}}-\mathrm{F}_{0}\right) / \mathrm{F}_{\mathrm{m}}$ (Kitajima and Butler 1975); ratio of photochemical to nonphotochemical

\section{Results}

Pigment composition: Data showed that high-light treatment led to decrease of the amount of $\mathrm{Chl}$ from 18 to $37 \%$, i.e. parameter LIC varied from 0.63 to 0.82 (Table 1). The changes were the biggest in $\mathrm{TF}_{1}$ and $\mathrm{TF}_{2}$ line grown in saline soils and $\mathrm{EE}_{0}$ grown in nonsaline soils. The decrease of the Chl content was accompanied by an increase of the $\mathrm{Chl} a / b$ ratio. The increase of this ratio in both studied Paulownia lines was smaller for plants grown in saline soils in comparison to those grown in nonsaline soil. Data also showed a decrease in the amount of Car after light stress, as the effect on the Car content was smaller in $\mathrm{EE}_{1}$ and $\mathrm{EE}_{2}$ in comparison to all variants of $\mathrm{TF}$ and $\mathrm{EE}_{0}$. The impact of light treatment on the pigment composition had smaller influence on Car/Chl ratio in EE plants in saline in comparison to nonsaline soil, i.e. the parameter LIC was bigger in saline soils (Table 1), while the light-induced changes in this ratio in TF plants grown in saline and nonsaline soils were similar, i.e. no significant differences between LIC parameters in saline and nonsaline soils.

PAM Chl fluorescence: The analysis of the Chl fluorescence curves revealed that the ratio $F_{v} / F_{m}$ decreased after light stress in both lines of Paulownia (Fig. 1); the effect processes, $F_{\mathrm{v}} / F_{0}=\left(F_{\mathrm{m}}-\mathrm{F}_{0}\right) / \mathrm{F}_{0}$ (Roháček 2002); the effective quantum yield of PSII photochemistry, $\mathrm{F}_{\mathrm{v}}{ }^{\prime} / \mathrm{F}_{\mathrm{m}}{ }^{\prime}=$ $\left(\mathrm{F}_{\mathrm{m}}{ }^{\prime}-\mathrm{F}_{0}{ }^{\prime}\right) / \mathrm{F}_{\mathrm{m}}{ }^{\prime}$ (Roháček 2002); the effective quantum yield of photochemical energy conversion of PSII, $\Phi_{\text {PSII }}=$ $\left(\mathrm{F}_{\mathrm{m}}{ }^{\prime}-\mathrm{F}_{\mathrm{s}}\right) / \mathrm{F}_{\mathrm{m}}{ }^{\prime}$; the photochemical quenching coefficient, $\mathrm{q}_{\mathrm{P}}=\left(\mathrm{F}_{\mathrm{m}}{ }^{\prime}-\mathrm{F}_{\mathrm{s}}\right) /\left(\mathrm{F}_{\mathrm{m}}{ }^{\prime}-\mathrm{F}_{0}{ }^{\prime}\right)($ Schreiber et al. 1986); the linear electron transport rate, $\mathrm{ETR}=\Phi_{\mathrm{PSII}} \times \mathrm{PFD} \times 0.5$ (Genty et al. 1989). The Chl fluorescence decrease ratio, $\mathrm{R}_{\mathrm{Fd}}$ was measured as in Stefanov et al. (2016). This ratio was calculated by the equation: $R_{F d}=F_{d} /\left(F_{m}-F_{d}\right)$, where $F_{d}$ is the fluorescence decrease from $F_{m}$ to steady state $\mathrm{Chl}$ fluorescence, it was measured using continuous saturated light (Lichtenthaler et al. 2005). The calculation of the constants was made as in Stefanov et al. (2016).

P $_{700}$ redox state measurements: The redox state of $P_{700}$ was investigated on leaf discs with a dual wavelength $(820 \mathrm{~nm})$ unit (ED 700DW-E, Walz, Germany) attached to a PAM101E (Walz, Germany) main control unit in the reflectance mode. The measurements were made as in Dankov et al. (2009).

Statistical analysis: The results were mean values from seven independent experiments. Analysis of variance (ANOVA) and Tukey's post-hoc tests were performed to reveal the statistical differences between groups in the studied parameters. The homogeneity of variance test were used to identify the assumptions of the parametric of $A N O V A$. Values of $p<0.05$ were considered as significant differences.

was more pronounced in the $\mathrm{EE}_{0}$ line (LIC was 0.71 ). The light-induced changes in the primary photochemistry of PSII were a result of the decreased $F_{v} / F_{0}$ (Fig. 1). The LIC parameters for the ratios $F_{v} / F_{m}$ and $F_{v} / F_{0}$ decreased for $T F_{1}$ and $\mathrm{TF}_{2}$ lines (i.e. salinity increased the effect of light stress), while the values of LIC for EE line grown in saline soils were higher than those in $\mathrm{EE}_{0}$. Data also revealed a light-induced inhibition of $\mathrm{q}_{\mathrm{P}}, \mathrm{F}_{\mathrm{v}}{ }^{\prime} / \mathrm{F}_{\mathrm{m}}$ ', the ETR, and $\Phi_{\mathrm{PSII}}$ (Fig. 2,3). In addition, data showed an increase of the effect of light stress in TF grown in saline soils, while for the EE line the effect was stronger in nonsaline in comparison to the saline soil.

The kinetics of the relaxation of Chl fluorescence excitation after single saturating pulse in dark-adapted leaves were used to assess the reoxidation of $\mathrm{Q}_{\mathrm{A}}^{-}$(Bukhov et al. 2001, Shirao et al. 2013). The relaxation curves could be fitted by two components (fast and slow component). The fast component was characterized with the rate constant $\mathrm{k}_{1}$ and the slow component was characterized with $\mathrm{k}_{2}$. The light treatment led to decrease of the both constants; the effect was more pronounced for rate constant $\mathrm{k}_{2}$ as the salinity enhanced the impact of the high light only in the TF line (Table 2). 
Table 1. Chlorophyll (Chl) and carotenoid (Car) composition in control and high light-treated leaves of Paulownia tomentosa $\times$ fortunei $(\mathrm{TF})$ and Paulownia elongata $\times$ elongata $(\mathrm{EE})$ grown in nonsaline $\left(\mathrm{TF}_{0}\right.$ and $\left.\mathrm{EE}_{0}\right)$ and saline $\left(\mathrm{TF}_{1}, \mathrm{TF}_{2}, \mathrm{EE}_{1}\right.$, and $\left.\mathrm{EE}_{2}\right)$ soils. LIC are the light-induced changes. Values in the same column followed by a different letter are significantly different at $p<0.05$. Small letters indicate differences between values, while capital letters show the differences between the coefficients of LIC.

\begin{tabular}{llclll}
\hline Sample & & Chl $(a+b)\left[\mu \mathrm{g} \mathrm{g}{ }^{-1}(\mathrm{FM})\right]$ & Chl $a / b$ & Car $\left.^{2} \mu \mathrm{g} \mathrm{g}^{-1}(\mathrm{FM})\right]$ & Car/Chl \\
\hline $\mathrm{TF}_{0}$ & Control & $1,201.62 \pm 46.96^{\mathrm{b}}$ & $3.052 \pm 0.077^{\mathrm{d}}$ & $388.87 \pm 26.71^{\mathrm{a}}$ & $0.324 \pm 0.001^{\mathrm{a}}$ \\
& Light & $948.75 \pm 32.99^{\mathrm{c}}$ & $4.029 \pm 0.112^{\mathrm{b}}$ & $275.42 \pm 7.74^{\mathrm{c}}$ & $0.290 \pm 0.008^{\mathrm{b}}$ \\
& LIC & $0.790 \pm 0.029^{\mathrm{A}}$ & $1.320 \pm 0.035^{\mathrm{A}}$ & $0.708 \pm 0.034^{\mathrm{B}}$ & $0.895 \pm 0.014^{\mathrm{B}}$ \\
$\mathrm{TF}_{1}$ & Control & $1,514.67 \pm 94.60^{\mathrm{a}}$ & $3.348 \pm 0.061^{\mathrm{c}}$ & $333.31 \pm 21.60^{\mathrm{ab}}$ & $0.220 \pm 0.040^{\mathrm{bc}}$ \\
& Light & $962.10 \pm 54.54^{\mathrm{c}}$ & $3.759 \pm 0.100^{\mathrm{b}}$ & $209.63 \pm 7.38^{\mathrm{d}}$ & $0.218 \pm 0.005^{\mathrm{c}}$ \\
& LIC & $0.635 \pm 0.038^{\mathrm{B}}$ & $1.123 \pm 0.025^{\mathrm{B}}$ & $0.629 \pm 0.031^{\mathrm{BC}}$ & $0.991 \pm 0.101^{\mathrm{AB}}$ \\
$\mathrm{TF}_{2}$ & Control & $1,458.60 \pm 73.07^{\mathrm{a}}$ & $3.377 \pm 0.051^{\mathrm{c}}$ & $334.96 \pm 24.18^{\mathrm{ab}}$ & $0.230 \pm 0.040^{\mathrm{bc}}$ \\
& Light & $989.72 \pm 67.22^{\mathrm{c}}$ & $3.771 \pm 0.074^{\mathrm{b}}$ & $212.65 \pm 1.85^{\mathrm{d}}$ & $0.215 \pm 0.003^{\mathrm{c}}$ \\
& LIC & $0.679 \pm 0.040^{\mathrm{B}}$ & $1.117 \pm 0.019^{\mathrm{B}}$ & $0.635 \pm 0.026^{\mathrm{BC}}$ & $0.935 \pm 0.088^{\mathrm{AB}}$ \\
$\mathrm{EE}_{0}$ & Control & $1,227.59 \pm 61.11^{\mathrm{b}}$ & $3.391 \pm 0.127^{\mathrm{c}}$ & $373.53 \pm 16.00^{\mathrm{a}}$ & $0.304 \pm 0.006^{\mathrm{b}}$ \\
& Light & $777.19 \pm 14.44^{\mathrm{d}}$ & $4.489 \pm 0.128^{\mathrm{a}}$ & $214.09 \pm 4.85^{\mathrm{d}}$ & $0.275 \pm 0.020^{\mathrm{b}}$ \\
& LIC & $0.633 \pm 0.022^{\mathrm{B}}$ & $1.324 \pm 0.044^{\mathrm{A}}$ & $0.573 \pm 0.019^{\mathrm{C}}$ & $0.905 \pm 0.042^{\mathrm{B}}$ \\
$\mathrm{EE}_{1}$ & Control & $1,161.54 \pm 33.77^{\mathrm{b}}$ & $3.321 \pm 0.072^{\mathrm{c}}$ & $341.26 \pm 13.47^{\mathrm{a}}$ & $0.294 \pm 0.010^{\mathrm{b}}$ \\
& Light & $947.44 \pm 39.50^{\mathrm{c}}$ & $3.928 \pm 0.180^{\mathrm{b}}$ & $295.21 \pm 15.39^{\mathrm{bc}}$ & $0.312 \pm 0.015^{\mathrm{ab}}$ \\
& LIC & $0.816 \pm 0.029^{\mathrm{A}}$ & $1.183 \pm 0.040^{\mathrm{B}}$ & $0.865 \pm 0.040^{\mathrm{A}}$ & $1.061 \pm 0.044^{\mathrm{A}}$ \\
$\mathrm{EE}_{2}$ & Control & $1,147.23 \pm 32.90^{\mathrm{b}}$ & $3.258 \pm 0.054^{\mathrm{c}}$ & $351.24 \pm 10.6^{\mathrm{a}}$ & $0.306 \pm 0.007^{\mathrm{b}}$ \\
& Light & $908.71 \pm 19.72^{\mathrm{c}}$ & $3.981 \pm 0.24^{\mathrm{b}}$ & $281.87 \pm 4.46^{\mathrm{c}}$ & $0.310 \pm 0.014^{\mathrm{ab}}$ \\
& LIC & $0.792 \pm 0.020^{\mathrm{A}}$ & $1.222 \pm 0.047^{\mathrm{AB}}$ & $0.803 \pm 0.018^{\mathrm{A}}$ & $1.013 \pm 0.034^{\mathrm{A}}$ \\
\hline
\end{tabular}

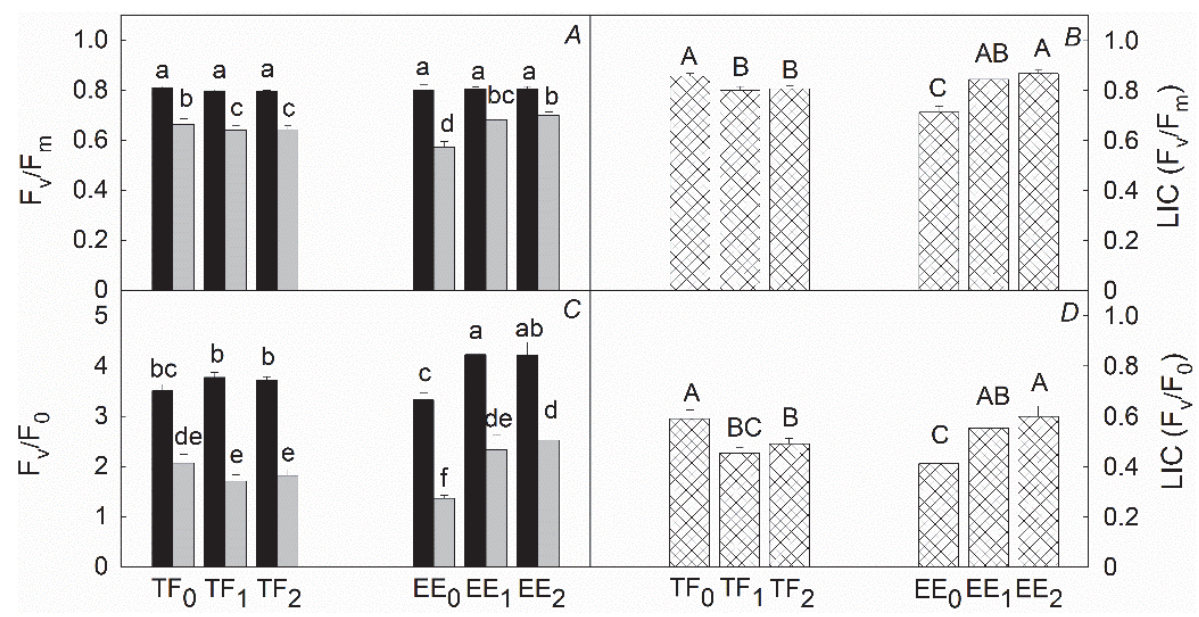

Fig. 1. Maximum quantum yield of primary photochemistry of PSII $\left(\mathrm{F}_{\mathrm{v}} / \mathrm{F}_{\mathrm{m}}\right)$ and ratio of photochemical to nonphotochemical processes $\left(\mathrm{F}_{\mathrm{v}} / \mathrm{F}_{0}\right)$ in control (black columns) and high light intensity-treated (grey columns) leaves of Paulownia tomentosa $\times$ fortunei $(\mathrm{TF})$ and Paulownia elongata $\times$ elongata $(\mathrm{EE})$ grown in nonsaline $\left(\mathrm{TF}_{0}\right.$ and $\left.\mathrm{EE}_{0}\right)$ and two saline $\left(\mathrm{TF}_{1}, \mathrm{TF}_{2}, \mathrm{EE}_{1}\right.$, and $\left.\mathrm{EE}_{2}\right)$ soils $(A, C)$. Lightinduced changes parameter (LIC) for $\mathrm{F}_{\mathrm{v}} / \mathrm{F}_{\mathrm{m}}$ ratio $(B)$ and $\mathrm{F}_{\mathrm{v}} / \mathrm{F}_{0}$ ratio $(D)$. Values of respective ratio followed by a different letter are significantly different at $p<0.05$. Small letters indicate differences between values, while capital letters show the differences between the coefficients of LIC.

All these changes in the PSII photochemistry were accompanied with an influence on the $\mathrm{R}_{\mathrm{Fd}}$ parameter (Fig. 4), which correlates with the net $\mathrm{CO}_{2}$ assimilation (Lichtenthaler et al. 2005). The parameter decreased after high-light treatment from 49 to $74 \%$ in the TF line in dependence on the soil salinity, as the salinity significantly increased the impact of the light stress. Data also revealed that the $\mathrm{R}_{\mathrm{Fd}}$ decreased in the EE line after light stress, but high salinity had no influence on the high light-induced changes of this parameter.

Oxidation-reduction kinetics of $\mathbf{P}_{700}$ : The postillumination dark-reduction kinetics of $\mathrm{P}_{700}{ }^{+}$in all studied plants was fitted by two negative exponents with rate constants $\mathrm{k}_{1}{ }^{\mathrm{P} 700}$ (for fast component) and $\mathrm{k}_{2}{ }^{\mathrm{P} 700}$ (for slow component), and amplitudes $\mathrm{A}_{1}$ and $\mathrm{A}_{2}$ for the fast and 


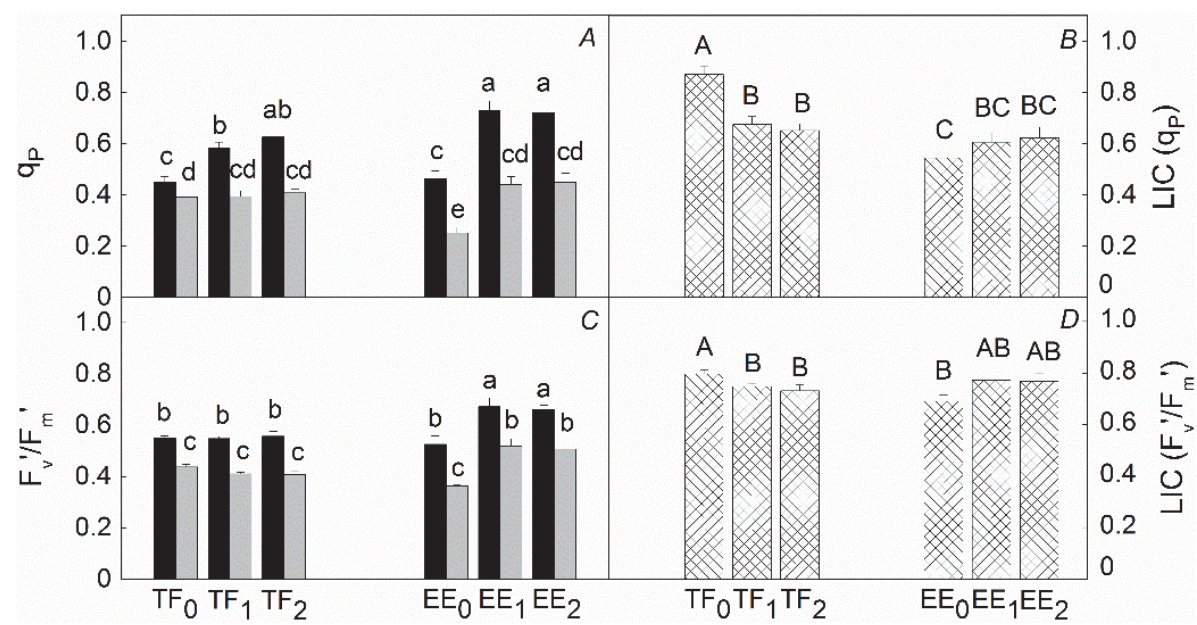

Fig. 2. Photochemical quenching coefficient (qP) and maximum quantum yield of photochemistry of PSII (LAS) ( $\left.\mathrm{F}_{\mathrm{v}}{ }^{\prime} / \mathrm{F}_{\mathrm{m}}{ }^{\prime}\right)$ in control (black columns) and high light intensity-treated (grey columns) leaves of Paulownia tomentosa $\times$ fortunei (TF) and Paulownia elongata $\times$ elongata $(\mathrm{EE})$ grown in nonsaline $\left(\mathrm{TF}_{0}\right.$ and $\left.\mathrm{EE}_{0}\right)$ and two saline $\left(\mathrm{TF}_{1}, \mathrm{TF}_{2}, \mathrm{EE}_{1}\right.$, and $\left.\mathrm{EE}_{2}\right)$ soils $(A, C)$. Light-induced changes parameter (LIC) for $\mathrm{q}_{\mathrm{p}}(B)$ and $\mathrm{F}_{\mathrm{v}}{ }^{\prime} / \mathrm{F}_{\mathrm{m}}{ }^{\prime}$ ratio $(D)$. Values of respective ratio followed by a different letter are significantly different at $p<0.05$. Small letters indicate differences between values, while capital letters show the differences between the coefficients of LIC.

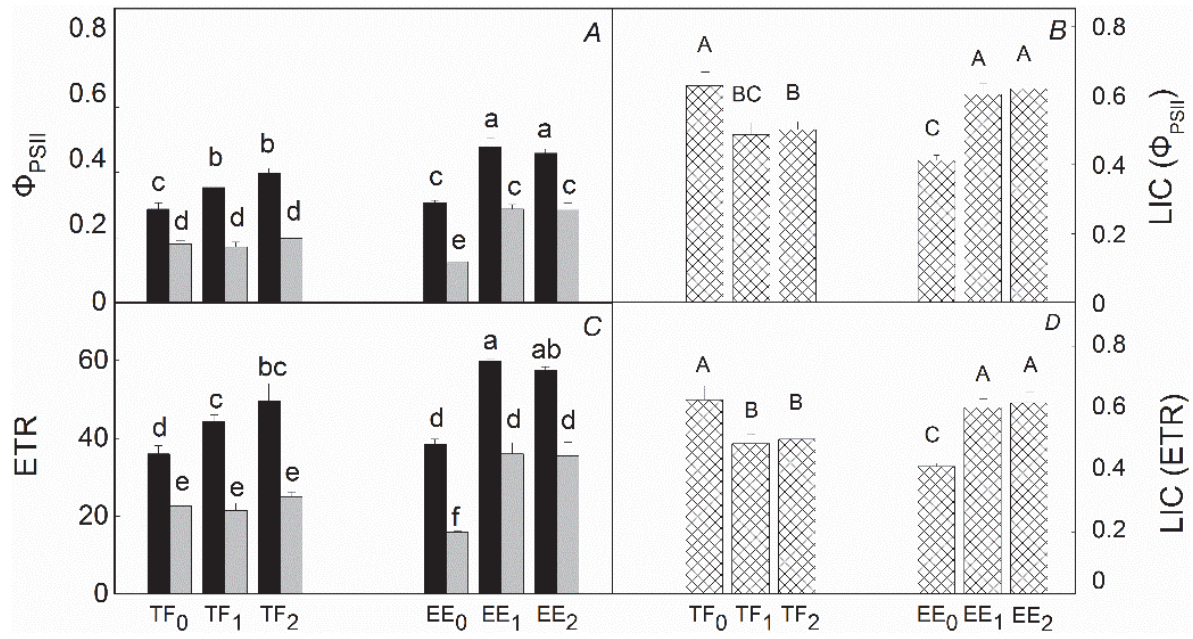

Fig. 3. The effective quantum yield of photochemical energy conversion of PSII ( $\Phi_{\text {PSII }}$ ) and linear electron transport rate (ETR) in control (black columns) and high light intensity-treated (grey columns) leaves of Paulownia tomentosa $\times$ fortunei (TF) and Paulownia elongata $\times$ elongata $(\mathrm{EE})$ grown in nonsaline $\left(\mathrm{TF}_{0}\right.$ and $\left.\mathrm{EE}_{0}\right)$ and two saline $\left(\mathrm{TF}_{1}, \mathrm{TF}_{2}, \mathrm{EE}_{1}\right.$, and $\left.\mathrm{EE}_{2}\right)$ soils $(A, C)$. Light-induced changes parameter (LIC) for $\Phi_{\text {PSII }}(B)$ and ETR $(D)$. Values of respective ratio followed by a different letter are significantly different at $p<0.05$. Small letters indicate differences between values, while capital letters show the differences between the coefficients of LIC.

the slow exponent, respectively. The calculated values of the rate constants and amplitudes for the studied plants are shown in Table 3. Data revealed that light stress led to an increase of the rate constants $\mathrm{k}_{1}{ }^{\mathrm{P} 700}$. The constant increased from 6 to $43 \%$, while the constant $\mathrm{k}_{2}{ }^{\mathrm{P} 700}$ decreased from 38 to $67 \%$ in both studied lines of Paulownia, grown in saline and nonsaline soils. The comparison of the values for the parameter LIC for the studied plants showed a strong

\section{Discussion}

In our previous study, we have investigated the effects of soil salinity on the functional activity of the photosynthetic influence of the salinity on the changes of the rate constant. The strongest influence on $\mathrm{k}_{1}{ }^{\mathrm{P} 700}$ was registered in $\mathrm{TF}_{2}$. The variation of the rate constants was accompanied with decrease of the ratio of amplitudes of both components $\left(\mathrm{A}_{1} / \mathrm{A}_{2}\right)$, as the effect was stronger for both Paulownia lines, grown in saline soils (more that $50 \%$ decrease of the ratio). The change in this ratio was a result of the decrease in $A_{1}$.

apparatus of Paulownia tomentosa $\times$ fortunei and Paulownia elongata $\times$ elongata and our results revealed 
Table 2. Effects of high-light stress on the rate constants (fast rate constant, $\mathrm{k}_{1}$, and slow rate constant, $\mathrm{k}_{2}$ ) of decay kinetics of flashinduced variable chlorophyll fluorescence in leaves of Paulownia tomentosa $\times$ fortunei $(\mathrm{TF})$ and Paulownia elongata $\times$ elongata (EE) grown in nonsaline $\left(\mathrm{TF}_{0}\right.$ and $\left.\mathrm{EE}_{0}\right)$ and saline $\left(\mathrm{TF}_{1}, \mathrm{TF}_{2}, \mathrm{EE}_{1}\right.$, and $\mathrm{EE}_{2}$ ) soils. LIC are light-induced changes. Values in the same column followed by a different letter are significantly different at $p<0.05$. Small letters indicate differences between values, while capital letters show the differences between the coefficients of LIC.

\begin{tabular}{llll}
\hline Sample & & $\mathrm{k}_{1}\left[\mathrm{~s}^{-1}\right]$ & $\mathrm{k}_{2}\left[\mathrm{~s}^{-1}\right]$ \\
\hline $\mathrm{TF}_{0}$ & Control & $0.966 \pm 0.063^{\mathrm{e}}$ & $0.079 \pm 0.002^{\mathrm{b}}$ \\
& Light & $0.910 \pm 0.062^{\mathrm{e}}$ & $0.056 \pm 0.001^{\mathrm{e}}$ \\
& LIC & $0.942 \pm 0.063^{\mathrm{A}}$ & $0.710 \pm 0.015^{\mathrm{A}}$ \\
$\mathrm{TF}_{1}$ & Control & $1.365 \pm 0.054^{\mathrm{c}}$ & $0.071 \pm 0.001^{\mathrm{c}}$ \\
& Light & $0.983 \pm 0.033^{\mathrm{e}}$ & $0.042 \pm 0.001^{\mathrm{g}}$ \\
& LIC & $0.720 \pm 0.026^{\mathrm{BC}}$ & $0.592 \pm 0.011^{\mathrm{B}}$ \\
$\mathrm{TF}_{2}$ & Control & $1.424 \pm 0.029^{\mathrm{c}}$ & $0.062 \pm 0.001^{\mathrm{d}}$ \\
& Light & $1.050 \pm 0.044^{\mathrm{de}}$ & $0.037 \pm 0.002^{\mathrm{h}}$ \\
& LIC & $0.737 \pm 0.023^{\mathrm{BC}}$ & $0.597 \pm 0.021^{\mathrm{B}}$ \\
$\mathrm{EE}_{0}$ & Control & $1.557 \pm 0.020^{\mathrm{a}}$ & $0.091 \pm 0.002^{\mathrm{a}}$ \\
& Light & $1.108 \pm 0.011^{\mathrm{d}}$ & $0.046 \pm 0.001^{\mathrm{f}}$ \\
& LIC & $0.712 \pm 0.008^{\mathrm{C}}$ & $0.505 \pm 0.011^{\mathrm{C}}$ \\
$\mathrm{EE}_{1}$ & Control & $1.505 \pm 0.005^{\mathrm{b}}$ & $0.050 \pm 0.003^{\mathrm{ef}}$ \\
& Light & $1.137 \pm 0.029^{\mathrm{d}}$ & $0.03 \pm 0.001^{\mathrm{i}}$ \\
& LIC & $0.755 \pm 0.011^{\mathrm{B}}$ & $0.600 \pm 0.028^{\mathrm{B}}$ \\
$\mathrm{EE}_{2}$ & Control & $1.424 \pm 0.024^{\mathrm{c}}$ & $0.063 \pm 0.003^{\mathrm{d}}$ \\
& Light & $1.117 \pm 0.057^{\mathrm{d}}$ & $0.038 \pm 0.001^{\mathrm{h}}$ \\
& LIC & $0.784 \pm 0.027^{\mathrm{B}}$ & $0.603 \pm 0.022^{\mathrm{B}}$ \\
\hline
\end{tabular}

that these hybrid lines are salt tolerant, but the EE line is less tolerant to salt stress than the TF line (Stefanov et al. 2016). It was found that the salt-induced changes in $\mathrm{Q}_{\mathrm{A}}^{-}$ reoxidation led to an increase of the photochemical quenching, stimulation of the electron transport, and improved the efficiency of the photochemical energy conversion, which was accompanied by an impact on the photosynthetic rate. In the present study, we focused on the impact of the high-light stress on the Paulownia lines grown in soils with different salinity.

It has been well documented that high-light conditions damage the components of the photosynthetic apparatus in thylakoid membranes (Kirchhoff 2014). The data in the present study showed that the high-light treatment led to decrease of the pigments (Chls and Car), which was accompanied by an increase of the $\mathrm{Chl} a / b$ ratio (Table 1 ). Taking into account that this ratio correlates with the amount of the LHCII and the degree of the membrane stacking (Apostolova et al. 2006, Stoichkova et al. 2006), it could be suggested that high light intensity caused changes in the organization of the thylakoid membranes. In addition, data revealed that light stress-induced changes in the pigment composition and the $\mathrm{Chl} a / b$ ratio strongly depended on the salinity of the soil in which plants were grown. At the same time, high-light treatment reduced the Car content in all studied plants (Table 1). Soil salinity increased the effect of the light stress in the TF line, while in the other Paulownia line the effect was smaller in the plants grown in saline soils. Data also revealed that in plants grown in saline soils, the amount of Car in EE was higher than those of TF, which was accompanied by a high ratio of $\mathrm{Car} / \mathrm{Chl}$ in the $\mathrm{EE}$ line.

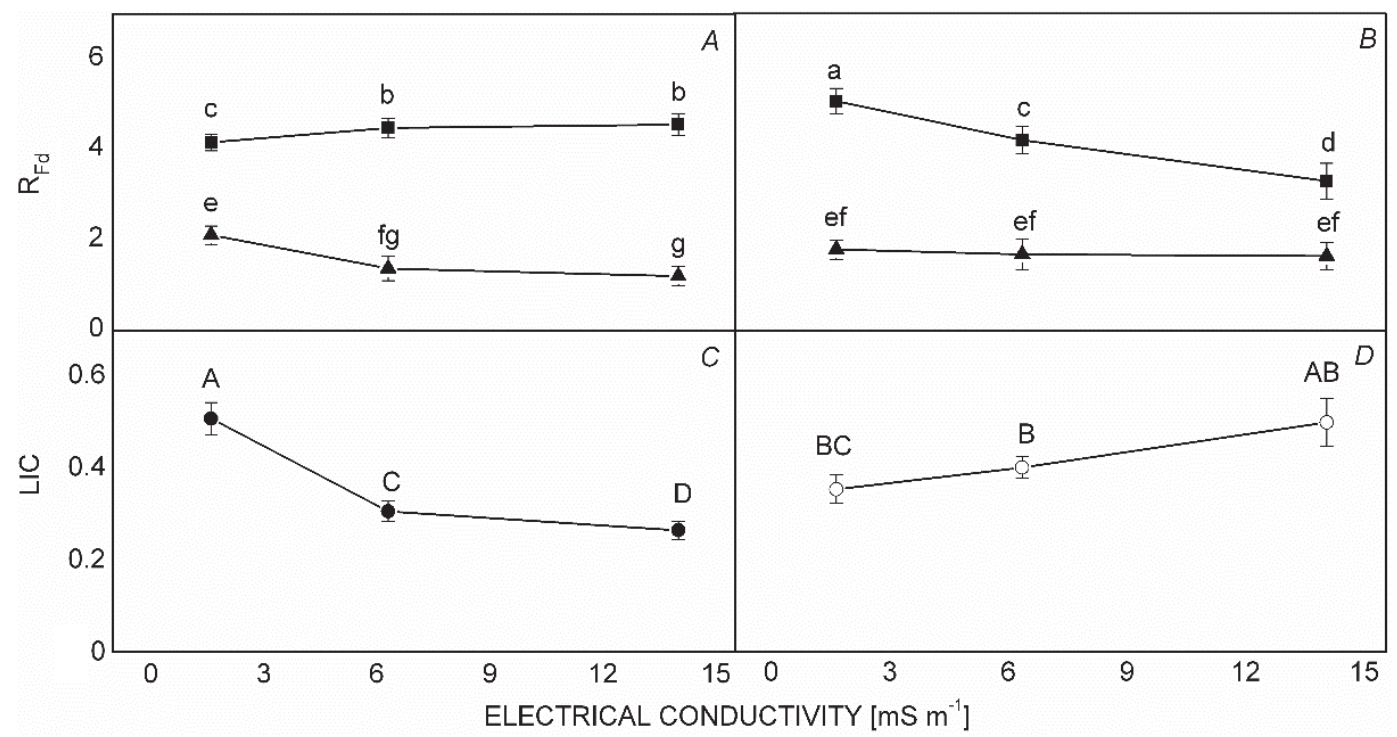

Fig. 4. Effects of high light intensity on chlorophyll fluorescence decrease ratio $\left(\mathrm{R}_{\mathrm{Fd}}\right)$ in leaves of Paulownia tomentosa $\times$ fortunei $(A)$ and Paulownia elongata $\times$ elongata $(B)$ depending on the electric conductivity of the soil: $(\boldsymbol{\square})$ control leaves and $(\boldsymbol{\Delta})$ high light-treated leaves. Light-induced changes parameter (LIC) for $\mathrm{R}_{\mathrm{Fd}}$ ratio in leaves of Paulownia tomentosa $\times$ fortunei $(C)$ and Paulownia elongata $\times$ elongata $(D)$.Values of respective parameter followed by a different letter are significantly different at $p<0.05$. Small letters indicate differences between values, while capital letters show the differences between the coefficients of LIC. 
Table 3. Effect of high light intensity on the fast and slow rate constants $\left(\mathrm{k}_{1}{ }^{\mathrm{P} 700}\right.$ and $\left.\mathrm{k}_{2}{ }^{\mathrm{P} 700}\right)$ and amplitudes ratio of two exponents $\left(\mathrm{A}_{1} / \mathrm{A}_{2}\right)$ of dark reduction of photosystem I reaction center $\left(\mathrm{P}_{700}{ }^{+}\right)$in leaves of Paulownia tomentosa $\times$fortunei (TF) and Paulownia elongata $\times$ elongata $(\mathrm{EE})$ grown in nonsaline $\left(\mathrm{TF}_{0}\right.$ and $\left.\mathrm{EE}_{0}\right)$ and two saline $\left(\mathrm{TF}_{1}, \mathrm{TF}_{2}, \mathrm{EE}_{1}\right.$, and $\left.\mathrm{EE}_{2}\right)$ soils. LIC are light-induced changes. Values in the same column followed by a different letter are significantly different at $p<0.05$. Small letters indicate differences between values, while capital letters show the differences between the coefficients LIC.

\begin{tabular}{lllll}
\hline Sample & & $\mathrm{k}_{1}{ }^{\mathrm{P} 700}\left[\mathrm{~s}^{-1}\right]$ & $\mathrm{k}_{2}{ }^{\mathrm{P} 700}\left[\mathrm{~s}^{-1}\right]$ & $\mathrm{A}_{1} / \mathrm{A}_{2}$ \\
\hline $\mathrm{TF}_{0}$ & Control & $0.305 \pm 0.002^{\mathrm{b}}$ & $0.045 \pm 0.001^{\mathrm{a}}$ & $0.691 \pm 0.020^{\mathrm{a}}$ \\
& Light & $0.324 \pm 0.006^{\mathrm{a}}$ & $0.015 \pm 0.001^{\mathrm{d}}$ & $0.479 \pm 0.030^{\mathrm{b}}$ \\
& LIC & $1.062 \pm 0.013^{\mathrm{C}}$ & $0.333 \pm 0.015^{\mathrm{C}}$ & $0.693 \pm 0.032^{\mathrm{A}}$ \\
$\mathrm{TF}_{1}$ & Control & $0.281 \pm 0.002^{\mathrm{d}}$ & $0.036 \pm 0.004^{\mathrm{b}}$ & $0.661 \pm 0.028^{\mathrm{a}}$ \\
& Light & $0.363 \pm 0.021^{\mathrm{a}}$ & $0.023 \pm 0.002^{\mathrm{c}}$ & $0.365 \pm 0.029^{\mathrm{c}}$ \\
& LIC & $1.292 \pm 0.042^{\mathrm{A}}$ & $0.639 \pm 0.063^{\mathrm{A}}$ & $0.552 \pm 0.034^{\mathrm{B}}$ \\
$\mathrm{TF}_{2}$ & Control & $0.271 \pm 0.008^{\mathrm{d}}$ & $0.032 \pm 0.001^{\mathrm{b}}$ & $0.678 \pm 0.030^{\mathrm{a}}$ \\
& Light & $0.388 \pm 0.042^{\mathrm{a}}$ & $0.020 \pm 0.003^{\mathrm{cd}}$ & $0.350 \pm 0.040^{\mathrm{cd}}$ \\
& LIC & $1.432 \pm 0.099^{\mathrm{A}}$ & $0.625 \pm 0.057^{\mathrm{A}}$ & $0.516 \pm 0.041^{\mathrm{B}}$ \\
$\mathrm{EE}_{0}$ & Control & $0.295 \pm 0.001^{\mathrm{c}}$ & $0.030 \pm 0.002^{\mathrm{bc}}$ & $0.736 \pm 0.025^{\mathrm{a}}$ \\
& Light & $0.333 \pm 0.016^{\mathrm{a}}$ & $0.018 \pm 0.001^{\mathrm{d}}$ & $0.525 \pm 0.030^{\mathrm{b}}$ \\
& LIC & $1.129 \pm 0.029^{\mathrm{BC}}$ & $0.600 \pm 0.037^{\mathrm{A}}$ & $0.713 \pm 0.032^{\mathrm{A}}$ \\
$\mathrm{EE}_{1}$ & Control & $0.282 \pm 0.005^{\mathrm{d}}$ & $0.033 \pm 0.001^{\mathrm{b}}$ & $0.712 \pm 0.023^{\mathrm{a}}$ \\
& Light & $0.364 \pm 0.028^{\mathrm{a}}$ & $0.015 \pm 0.002^{\mathrm{d}}$ & $0.316 \pm 0.010^{\mathrm{cd}}$ \\
& LIC & $1.291 \pm 0.061^{\mathrm{A}}$ & $0.455 \pm 0.037^{\mathrm{B}}$ & $0.444 \pm 0.014^{\mathrm{C}}$ \\
$\mathrm{EE}_{2}$ & Control & $0.284 \pm 0.003^{\mathrm{d}}$ & $0.034 \pm 0.001^{\mathrm{b}}$ & $0.656 \pm 0.031^{\mathrm{a}}$ \\
& Light & $0.359 \pm 0.030^{\mathrm{a}}$ & $0.016 \pm 0.002^{\mathrm{d}}$ & $0.279 \pm 0.023^{\mathrm{d}}$ \\
& LIC & $1.264 \pm 0.059^{\mathrm{AB}}$ & $0.471 \pm 0.036^{\mathrm{B}}$ & $0.425 \pm 0.028^{\mathrm{C}}$ \\
\hline
\end{tabular}

The changes in the thylakoid membranes after light treatment in all studied plants were connected with a decrease of the $F_{v} / F_{m}$ ratio (Fig. 1), which indicates photoinhibitory changes of the PSII complex and likely involves inactivation and/or disassembly of PSII core complex (Adams et al. 2006). The values of this ratio from 0.4 to 0.7 after light stress were determined as a moderate level of photoinhibition (Adams et al. 2006). The values of $\mathrm{F}_{\mathrm{v}} / \mathrm{F}_{\mathrm{m}}$ in all studied Paulownia plants were from 0.57 to 0.70 , thus, we could conclude that light treatment led to moderate level of photoinhibition in both hybrid lines. The studied Paulownia lines showed a comparatively high $\mathrm{Chl} a / b$ ratio (Table 1 ), which suggests a small number of thylakoids in grana (Apostolova et al. 2006, Stoichkova et al. 2006). Previous studies with pea have been shown that the pea plants with less stacked membranes and more stroma-exposed thylakoids are less susceptible to photoinhibition (Aro et al. 1993a, Dankov et al. 2011, Apostolova 2013). This could explained the moderate photoinhibition in studied Paulownia lines. Another useful parameter, $\mathrm{F}_{\mathrm{v}}{ }^{\prime} / \mathrm{F}_{\mathrm{m}}{ }^{\prime}$ (effective quantum yield of PSII), characterizes the PSII quantum efficiency at the lightadapted state. This parameter also declined after the highlight treatment $(20-30 \%)$ in all studied plants. The modification of the PSII complex after exposure to high light decreased $\mathrm{F}_{\mathrm{v}} / \mathrm{F}_{0}, \mathrm{q}_{\mathrm{P}}, \Phi_{\mathrm{PSII}}$, and ETR (Figs. 1, 2, 3). Salinity led to the increase of the effect of the light stress on these parameters in TF, while in the EE line the effect was stronger in plants grown in nonsaline soils in comparison to those grown in saline soils. In addition, the absolute values of the above parameters for the plants grown in saline conditions were higher for $\mathrm{EE}$ than those for $\mathrm{TF}$, which suggested a decrease of the overexcitation of PSII in the EE line.

High light-induced decrease in the $\mathrm{q}_{\mathrm{P}}$ and ETR showed the decreased ability of the photosynthetic apparatus to maintain $\mathrm{Q}_{\mathrm{A}}$ in the oxidized state and a reduction in the amount of the "open" PSII reaction centers (Figs. 2, 3). In addition, our data revealed the decrease of the rate constants $\left(\mathrm{k}_{1}\right.$ and $\left.\mathrm{k}_{2}\right)$ of the Chl fluorescence decay after excitation by a saturating light pulse which suggests a restriction of the electron flow from $\mathrm{Q}_{\mathrm{A}}$ to plastoquinone (Table 2). Similar influence of the electron flow from $Q_{A}$ to plastoquinone has been shown in previous studies of plants under other abiotic stress factors (Lichthentaler et al. 2005, Gong et al. 2008). In addition, experimental data showed higher values of $\mathrm{k}_{1}$ after high-light treatment for EE line in comparison to the TF line (Table 2). It could be suggested that the light-induced changes of the reoxidation of $\mathrm{Q}_{\mathrm{A}}$ were more pronounced in TF in comparison to the EE line.

The values of the $\mathrm{R}_{\mathrm{Fd}}$ parameter after light treatment of the studied plants were from 1.2 to 2.0 (Fig. 4). Taking into account that this parameter reflects the photosynthetic capacity and the $\mathrm{CO}_{2}$ fixation rate (Lichtenthaler et al. 2005), it could suggest an inhibition of the net photosynthetic rate after high-light treatment; the effect was stronger in the TF line in saline soils. Data revealed also a 
strong impact of the salinity on the light-induced changes in this parameter in the TF line.

The dark reduction kinetics of the far-red-induced absorption changes around $820 \mathrm{~nm}$ were used to assess the effects of high light on the PSI. It has been suggested that the biphasic kinetic of the dark reduction of $\mathrm{P}_{700}{ }^{+}$after turning on the far-red light occurrs due to reduction of two different populations of PSI located in different domains of the thylakoid membranes or originated from two electron donor systems (Albertsson 1995). Bukhov et al. (2002) have been suggested that fast operating pathways (with rate constant $\mathrm{k}_{1}{ }^{\mathrm{P} 700}$ and amplitude $\mathrm{A}_{1}$ ) could be driven by enzymes located in stroma lamellae, while enzymes mediating the slow pathways (with rate constant $\mathrm{k}_{2}{ }^{\mathrm{P} 700}$ and amplitude $\mathrm{A}_{2}$ ) are in grana thylakoids. The highlight treatment led to increase of $\mathrm{k}_{1}{ }^{\mathrm{P} 700}$, which indicates an increase of the cyclic electron transport around PSI in the stroma lamellae and the effect was enhanced by the soil salinity in the TF line. Data also revealed a decrease of $\mathrm{k}_{2}{ }^{\mathrm{P} 700}$ in all studied plants, which could be a result of the impact of the high light on the linear electron transport.

\section{References}

Adams W., Zarter C., Mueh K.E. et al.: Energy dissipation and photoinhibition: A continuum of photoprotection. - In: Demmig-Adams B., Adams W., Mattoo A. (ed.): Photoprotection, Photoinhibition, Gene Regulation and Environment. Pp. 49-64. Springer, Dordrecht 2006.

Akram A., Ashraf M.: Improvement in growth, chlorophyll pigments and photosynthetic performance in salt-stressed plants of sunflower (Helianthus annuus L.) by foliar application of 5-aminolevulinic acid. - Agrochimica 55: 94-104, 2011.

Albertsson P.: The structure and function of the chloroplast photosynthetic membrane - a model for the domain organization. - Photosynth. Res. 46: 141-149, 1995.

Allakhverdiev S., Nishiyama Y., Miyairi S. et al.: Salt stress inhibits the repair of photodamaged photosystem II by suppressing the transcription and translation of $p s b A$ genes in Synechocystis. - Plant Physiol. 130: 1443-1453, 2002.

Apostolova E.: Effect of high-light on photosynthetic apparatus with different content of anionic lipids and organization of light-harvesting complex of photosystem II. - Acta Physiol. Plant. 35: 975-978, 2013.

Apostolova E., Dobrikova A., Ivanova P. et al.: Relationship between the organization of the PSII supercomplex and the functions of the photosynthetic apparatus. - J. Photoch. Photobio. B 83: 114-122, 2006.

Aro E., McCaffery S., Anderson J.M.: Photoinhibition and D1 degradation in peas acclimated to different growth irradiation. - Plant Physiol. 103: 835-843, 1993 a.

Aro E., Virgin I., Andersson B.: Photoinhibition of photosystem II. Inactivation, protein damage and turnover. - Biochim. Biophys. Acta 1143: 113-134, 1993b.

Ashraf M., Harris P.: Photosynthesis under stressful environments: an overview. - Photosynthetica 51: 163-190, 2013.

Barth C., Krause G., Winter K.: Responses of photosystem I compared with photosystem II to high-light stress in tropical shade and sun leaves. - Plant Cell Environ. 24: 163-176, 2001.

Bukhov N., Egorova E., Carpentier R.: Electron flow to
Conclusions: In summary, data revealed that high-light treatment influenced functions of both photosystems in studied lines of Paulownia. Light stress led to decrease of the chlorophyll and carotenoid contents, influenced the reoxidation of $\mathrm{Q}_{\mathrm{A}}{ }^{-}$(restriction of the electron flow from $\mathrm{Q}_{\mathrm{A}}$ to plastoquinone), decreased the efficiency of the photochemical energy conversion, stimulated the cyclic electron transport, and delayed the net $\mathrm{CO}_{2}$ assimilation rate $\left(\mathrm{R}_{\mathrm{Fd}}\right.$ parameter $)$. The salinity increased the susceptibility of the PSII only in TF, while in EE the effects were smaller for the plants grown in saline soils than for those grown in nonsaline soils. The increased effects of the high-light stress under soil salinity could be a result of stronger reduction of the amount of the Cars and $\mathrm{Car} / \mathrm{Chl}$ ratio as well as the strong influence on the reoxidation of the $\mathrm{Q}_{\mathrm{A}}^{-}$in $\mathrm{TF}$ in comparison to the $\mathrm{EE}$ line. The results indicated that the salt-tolerant lines TF and EE are sensitive to high-light stress. The results in this study would be useful in development of new lines Paulownia which are tolerant to both the salinity and the light stress.

photosystem I from stromal reductants in vivo: the size of the pool of stromal reductants controls the rate of electron donation to both rapidly and slowly reducing photosystem I units. Planta 215: 812-820, 2002.

Bukhov N., Samson G., Carpentier R.: Non photosynthetic reduction of the intersystem electron transport chain of chloroplasts following heat stress. The pool size of stromal reductants. - Photochem. Photobiol. 74: 438-443, 2001.

Dąbrowski P., Baczewska A.H., Pawluśkiewicz B. et al.: Prompt chlorophyll $a$ fluorescence as a rapid tool for diagnostic changes in PSII structure inhibited by salt stress in perennial ryegrass. - J. Photoch. Photobio. B 157: 22-31, 2016.

Dąbrowski P., Kalaji H., Baczewska A.H. et al.: Delayed chlorophyll $a$ fluorescence, MR 820, and gas exchange changes in perennial ryegrass under salt stress. - J. Lumin. 183: 322$333,2016$.

Dąbrowski P., Pawluskiewicz B., Baczewska A.H. et al.: Chlorophyll $a$ fluorescence of perennial ryegrass (Lolium perenne L.) varieties under long term exposure to shade. Zemdirbyste 102: 305-312, 2015.

Dankov K., Busheva M., Stefanov D., Apostolova E.: Relationship between the degree of carotinoid depletion and function of photosynthetic apparatus. - J. Photochem. Photobiol. B. 96: 4956, 2009.

Dankov K., Dobrikova A., Ughy B. et al.: LHCII organization and thylakoid lipids affect the sensitivity of the photosynthetic apparatus to high-light treatment. - Plant Physiol. Bioch. 49: 629-635, 2011.

Genty B., Briantais G., Baker N.: The relationship between quantum yield of photosynthetic electron transport and quenching of chlorophyll fluorescence. - Biochim. Biophys. Acta 990: 87-92, 1989.

Goh T., Joi S., Mimura T., Fukaki H.: The establishment of asymmetry in Arabidopsis lateral root founder cells is regulated by LBD16/ASL18 and related LBD/ASL proteins. Development 139: 883-893, 2012. 
Gong H., Tang Y., Wang J. et al.: Characterization of photosystem II in salt stress cyanobacterial Spirulina platensis cells. - Biochim. Biophys. Acta 1777: 488-495, 2008.

Grieve C., Suarez D.: Purslane (Portulaca oleracea L.): a halophytic crop for drainage water reuse systems. - Plant Soil 192: 277-283, 1997.

Hakala M., Tuominen I., Keränen M. et al.: Evidence for the role of the oxygen-evolving manganese complex in photoinhibition of photosystem II. - Biochim. Biophys. Acta 1706: 68-80, 2005.

Hasanuzzaman M., Nahar K., Fujita M.: Plant response to salt stress and role of exogenous protectants to mitigate saltinduced damages. - In: Ahmed P., Azooz M., Prasad M. (ed.): Ecophysiology and Responses of Plants Under Salt Stress. Pp. 25-87. Springer, New York 2013.

Hasanuzzaman M., Fujita M., Islam M. et al.: Performance of four irrigated rice varieties under different levels of salinity stress. - Int. J. Integr. Biol. 6: 85-90, 2009.

Ioannidis N., Ortigosa M., Veramendi J. et al.: Remodeling of tobacco thylakoids by over-expression of maize plastidial transglutaminase. - Biochim. Biophys. Acta 1787: 1215-1222, 2009.

Ivanova K., Dimitrova V., Georgieva T., Markovska Y.: Effect of soil salinity on growth, gas exchange and antioxidant defense of two Paulownia lines. - Gen. Plant Physiol. 4: 163173, 2014.

Jiang Y., Dinga X., Zhang D. et al.: Soil salinity increases the tolerance of excessive sulfur fumigation stress in tomato plants. - Environ. Exp. Bot. 133: 70-77, 2017.

Kalaji H., Schansker G., Brestic M. et al.: Frequently asked questions about chlorophyll fluorescence, the sequel. Photosynth. Res. 132: 13-66, 2017.

Kingsbury R., Epstein E., Pearcy R.: Physiological responses to salinity in selected lines of wheat. - Plant Physiol. 74: 417-423, 1984.

Kirchhoff H.: Structural changes of the thylakoid membrane network induced by high light stress in plant chloroplasts. Philos. T. R. Soc. B. 369: 20130225, 2014.

Kitajima M., Butler W.: Quenching of chlorophyll fluorescence and primary photochemistry in chloroplasts by dibromothymoquinone. - Biochim. Biophys. Acta 376: 105-115, 1975.

Lichtenthaler H.: Chlorophylls and carotenoids: pigments of photosynthetic biomembranes. - Method. Enzymol. 148: 350$382,1987$.

Lichtenthaler K., Langsdorf G., Lenk S., Buschmann C.: Chlorophyll fluorescence imaging of photosynthetic activity with the flash-lamp fluorescence imaging system. Photosynthetica 43: 355-369, 2005.

Loreto F., Centritto M., Chartzoulakis K.: Photosynthetic limitations in olive cultivars with different sensitivity to salt stress. Plant Cell Environ. 26: 595-601, 2003.

Lu C., Jiang B., Wang B., Kuang T.: Photosystem II photochemistry and photosynthetic pigment composition in salt adapted chalophyte Artemisia anethifolia grown under outdoor conditions. - J. Plant Physiol. 160: 403-408, 2003.

Lu C., Qiu N., Lu Q. et al.: Does salt stress lead to increased susceptibility of photosystem II to photoinhibition and changes in photosynthetic pigment composition in halophyte Suaeda salsa grown outdoors? - Plant Sci. 163: 1063-1068, 2002.

Masojídek J., Hall D.: Salinity and drought stress are amplified by high irradiance in sorghum. - Photosynthetica 27:
$159-171,1992$

Misra A.N., Sahu S., Misra M. et al.: Sodium chloride induced changes in leaf growth, and pigment and protein contents in two rice cultivars. - Biol. Plantarum 39: 257-262, 1997.

Misra A., Sahu S., Meera I. et al:: Root growth of salt susceptible and a salt resistant rice (Oryza sativa $L$ ) during seedling establishment under $\mathrm{NaCl}$ salinity. - J. Agr. Crop Sci. 178: 914, 1997.

Misra S.K., Subrahmanyam D., Singhal G.: Interrelationship between salt and light stress on primary processes on photosynthesis. - J. Plant Physiol. 138: 92-96, 1991.

Murata N., Takahashi S., Nishiyama Y., Allakhvedriev S.: Photoinhibition of photosystem II under environmental stress. - Biochim. Biophys. Acta 1767: 414-421, 2007.

Nishiyama Y., Allakhverdiev S., Murata N.: A new paradigm for the action of reactive oxygen species in the photoinhibition of photosystem II. - Biochim. Biophys. Acta 1757: 742-749, 2006.

Parida A., Das A.: Salt tolerance and salinity effects on plants: a review. - Ecotoxicol. Environ. Safe. 60: 324-349, 2005.

Roháček K.: Chlorophyll fluorescence parameters: the definitions, photosynthetic meaning, and mutual relationships. Photosynthetica 40: 13-29, 2002.

Schreiber U., Schliwa U., Bilger W.: Continuous recording of photochemical and non-photochemical chlorophyll fluorescence quenching with a new type of modulation fluorometer. Photosynth. Res. 10: 51-62, 1986.

Sharma P., Hall D.: Interaction of salt stress and photoinhibition on photosynthesis in barley and sorghum. - J. Plant Physiol. 138: $614-619,1991$

Shirao M., Kuroki S., Kaneko K. et al.: Gymnosperms have increased capacity for electron leakage to oxygen (Mehler and PTOX reactions) in photosynthesis compared with angiosperms. - Plant Cell Physiol. 54: 1152-1163, 2013.

Shu S., Guo R., Sun J., Yuan Y.: Effects of salt stress on the structure and function of the photosynthetic apparatus in Cucumis sativus and its protection by exogenous putrescine. Physiol. Plantarum 146: 285-296, 2012.

Sonoike K.: Degradation of $p s a B$ gene product, the reaction center subunit of photosystem I, is caused during photoinhibition of photosystem I: Possible involvement of active oxygen species. - Plant Sci. 115: 157-164, 1996.

Stefanov M., Yotsova K., Rashkov G. et al.: Effects of salinity on the photosynthetic apparatus of two Paulownia lines. - Plant Physiol. Bioch. 101: 54-59, 2016.

Stoichkova K., Busheva M., Apostolova E., Andreeva A.: Changes in the energy distribution in mutant thylakoid membranes of pea with modified pigment content II. Changes due to magnesium ions concentration. - J. Photoch. Photobio. B. 83: 11-20, 2006.

Takahashi S., Badger M.: Photoprotection in plants: a new light on photosystem II damage. -Trends Plant Sci. 16: 53-60, 2011.

Takahashi S., Murata N.: How do environmental stresses accelerate photoinhibition? - Trends Plant Sci. 13: 178-182, 2008.

Vass I.: Molecular mechanisms of photodamage in the photosystem II complex. - Biochim. Biophys. Acta 1817: 209217, 2012.

Wang R., Hua C., Zhou F., Zjou C.: Effects of $\mathrm{NaCl}$ stress on photochemical activity and thylakoid membrane polypeptide composition of a salt-tolerant and salt-sensitive rice cultivar. Photosynthetica 47: 125-127, 2009. 